past year completed an online survey. Physicians (243 pulmonologists, 203 rheumatologists, 40 internal medicine physicians) from the US, Japan, Germany, France, Italy, Spain and UK participated. ILD prevalence and treatment patterns in the US were analysed based on insurance claims from patients with $\geq 2$ claims with an ILD diagnosis between 2014 and 2016 (ICD-9/10 codes) and $\geq 1$ visit to a pulmonologist in the 3 years.

Results: Analysis of US claims identified 21592 patients with autoimmune ILD Rheumatoid arthritis ILD (RA-ILD) and systemic sclerosis ILD (SSc-ILD) were the most prevalent ILDs across all autoimmune rheumatic diseases. The course of the patient journey is summarised (figure 1). Most patients with autoimmune-associated ILD initially present to a rheumatologist or a primary care doctor. Both pulmonologists and rheumatologists play a key role in detection and diagnosis of ILD; however US claims data suggest that the former are more likely to make the diagnosis. Although there is significant inter-patient variation, diagnosis of ILD is estimated to take approximately 9-12 months after symptoms develop. In general ILD is diagnosed earlier in SSc. Management of patients with autoimmune-associated ILD is typically multidisciplinary, involving both a rheumatologist and a pulmonologist. The physician survey suggested that $24 \%>31 \%$ of patients with autoimmune-associated ILD develop PF-ILD; detection can take up to 1 year. The majority of physicians use corticosteroids as a first line treatment across autoimmune rheumatic diseases; cyclophosphamide and mycophenolate mofetil were the second and third first line option for SSc-ILD. Physicians estimate the total disease course in patients with autoimmune-associated PF-ILD to be approximately $5-7$ years.

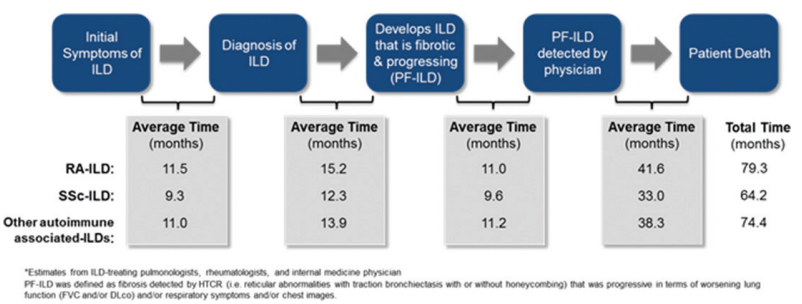

Abstract SAT0593 - Figure 1. Physician* Estimated PF-ILD Disease Course in patients with autoimmune rheumatic diseases

Conclusions: Physicians who manage patients with autoimmune diseases estimate that $24 \%>31 \%$ develop PF-ILD. Delayed referral to a pulmonologist or rheumatologist is likely to delay diagnosis and management of PF-ILD. Life expectancy for these patients is believed to be similar to patients with IPF. There is an unmet need for treatments that slow or stabilise disease progression of PFILD.

Disclosure of Interest: A. Fischer Consultant for: Boehringer Ingelheim, M. Wijsenbeek: None declared, M. Kreuter: None declared, B. Mounir: None declared, L. Zouad-Lejour: None declared, V. Acciai: None declared, C. Wells: None declared, M. Quaresma: None declared, C. Denton: None declared DOI: 10.1136/annrheumdis-2018-eular.4422

\section{SAT0594 WHICH ONE IS MORE VALUABLE FOR DIAGNOSIS OF ADULT ONSET STILL'S DISEASE? SOLELY NEUTROPHILIA OR LEUKOCYTOSIS WITH NEUTROPHILIA?}

E. Bilgin ${ }^{1}$, A. Erden ${ }^{2}$, B. Armagan², L. Kılıç ${ }^{2}$, A. Sarı ${ }^{2}$, G. Yardımcl ${ }^{2}$, E. Bilgin ${ }^{3}$, A. Akdoğan ${ }^{1}$, Ö. Karadağ ${ }^{2}$, S. Apraş Bilgen², I. Ertenli ${ }^{2}$, S. Kiraz ${ }^{2}$, U. Kalyoncu². ${ }^{1}$ Internal Medicine; ${ }^{2}$ Internal Medicine, Division of Rheumatology, ${ }^{3}$ Physical Medicine and Rehabilitation, Hacettepe University Faculty of Medicine, Ankara, Turkey

Background: Adult onset Still's disease (AOSD) is a rare, auto-inflammatory disease that has unknown etiology and poorly defined pathogenesis. To date, there are several classification criteria, available for AOSD, but most commonly used one is proposed by Yamaguchi et al(. ${ }^{1}$ One of the major items of this set of criteria is leukocytosis with neutrophilia.
Objectives: To usefulness of solely neutrophilia instead of leukocytosis with neutrophilia for the Yamaguchi criteria.

Methods: Sixty-one AOSD patients followed at Hacettepe University department of rheumatology were included to analysis. Diagnosis of AOSD was based on physicians' decision, but Yamaguchi criteria was applied for all patients, as well. Complete blood test with differential was noted at the time of diagnosis of AOSD. One of the major criteria of Yamaguchi criteria was "leukocytosis with neutrophilia (defined as more than $80 \%$ of leukocytes would be granulocyte)". Leukocytosis $\left[\left(>10000 / \mathrm{mm}^{3}\right) \times 1000\right]$ and neutrophilia $\left[\left(6400 / \mathrm{mm}^{3}\right) \times 1000\right]$ were defined according to normal upper limits of our laboratory. To compare with Yamaguchi criteria, neutrophi/leukocyte ratio for all patients were calculated. Descriptive statistics for non-normally distributed countable data were given as median and interquartile range (Med [IQR]). $\mathrm{p}<0,05$ was considered as statistically significant.

Results: Total 61 patients (46 (75\%) female) were recruited. Prevalence of major and minor Yamaguchi criteria were as follow: fever in all patients, arthralgia in 58 (95\%) patients, rash in $43(71 \%)$ patients, sore throat in $48(79 \%)$ patients, lymphadenopathy and/or splenomegaly in $23(38 \%)$ patients, absence of RF and ANA in 58 (96\%) patients, elevated liver enzymes in $47(77 \%)$ patients. Median leukocyte and neutrophil count were $13.5\left(\right.$ IQR;10.1-18,9) $\times 1000 / \mathrm{mm}^{3}, 12$ (IQR;7.2-17.6) x 1000/ $\mathrm{mm}^{3}$, respectively. "Neutrophilia >UNL" was significantly more prevalent than "leukocytosis with neutrophilia $>80 \%$ " $(51$ (83,6\%) vs. 37 $(60,6 \%), p<0,001)$. Overall, $14(23 \%)$ patients would have one more positive major criteria if "neutrophilia >UNL" would be used instead of "leukocytosis with neutrophilia $>80 \%$ ". When current Yamaguchi criteria (including leukocytosis with neutrophilia $>80 \%)$ applied to patients with AOSD, $57(93,5 \%)$ of 61 patients were met the criteria. However, when "neutrophilia $>$ UNL" was used instead of "leukocytosis with neutrophilia $>80 \%$ ", all patients were met the revised criteria.

Conclusions: As all patients who had leukocytosis also had neutrophilia but it was not vice versa. In other words, choosing "leukocytosis with neutrophilia $>80 \%$ " instead of "neutrophilia $>$ UNL" can underdiagnose AOSD approximately in $\% 7$ of patients according to Yamaguchi criteria. Moreover, Physicians should be keep in mind that reactive hemophagocytosis may influence the count of leukocyte. Consequently, using "neutrophilia $>\mathrm{UNL}$ " as a criteria instead of "leukocytosis with neutrophilia > 80 " may be more appropriate for the diagnosis of AOSD in real life.

\section{REFERENCE:}

[1] Yamaguchi M, Ohta A, Tsunematsu T, Kasukawa R, Mizushima Y, et al. Preliminary criteria for classification of adult Still's disease. J Rheumatol 1992;19:424-30.

Disclosure of Interest: None declared DOI: 10.1136/annrheumdis-2018-eular.6168

\section{SAT0595 \\ ANALYSIS OF RECURRENCES AFTER SUSPENSION OF IMMUNOSUPPRESSIVE TREATMENT IN NON- INFECTIOUS UVEITIS}

M. Uriarte ${ }^{1}$, C. Martín ${ }^{2}$, J. Gonzalez ${ }^{2}$, R. García de Vicuña ${ }^{1}$, E. Pato ${ }^{3}$, M. Gorroño ${ }^{4}$, Á. M. Aparicio ${ }^{5}$, M. Corder $0^{6} .{ }^{1}$ Rheumatology; ${ }^{2}$ Opthalmology, Hospital Universitario La Princesa; ${ }^{3}$ Rheumatology, Hospital Clínico San Carlos; ${ }^{4}$ Opthalmology, Hospital Príncipe de Asturias, Madrid; ${ }^{5}$ Rheumatology, Hospital Virgen de la Salud, Toledo; ${ }^{6}$ Opthalmology, Hospital Universitario de León, León, Spain

Background: Uveitis is the most common ocular inflammatory disease. According to the classification, non-infectious uveitis $70 \%$ of the total, presenting a chronic course and with it, an increased risk of complications. The phased therapeutic approach in ophthalmology is well established and is based on the efficacy of synthetic and biological immunosuppressive therapy. ${ }^{1}$ However, we do not have evidence-based protocols that allow us to know how long to maintain them, or when to interrupt them.

Objectives: The main objective is to evaluate the free time without ocular inflammatory activity after the withdrawal of the synthetic and/or biological immunosuppressive treatment in patients with non-infectious uveitis.

As secondary objectives are collected the epidemiological and clinical characteristics, the distribution of the different immunosuppressive drugs employed and 
analysed the cases of recurrence after the interruption of treatment, and the need of reintroduction.

Methods: A retrospective cohort multicenter study was conducted in patients with a diagnosis of non-infectious uveitis followed in a multidisciplinary unit, that after two or more years of ocular and extraocular inactivity, the inmunossuppresive treatment was suspended. It was defined inactive uveitis as cell Tyndall 0 in anterior and vitreous chamber, as well as the absence of other signs of active inflammation (retinal infiltrates, choroid and vasculitis and/or papillitis with angiographic leakage)

Demographic characteristics, anatomical location and laterality of the uveitis, visual acuity at the beginning and end of the study and the drugs used were recorded.

Results: We analysed 48 patients with an average age at the onset of immunosuppressive treatment of 39.3 years ( \pm 16 years). $85.4 \%$ of the uveitis were bilateral. The main diagnoses are described in table 1 . In $56.3 \%$ of cases a single immunosuppressant was used. Cyclosporine was the most employed (72.9\%) and methotrexate was the most used in monotherapy (83.3\%). $83 \%$ of patients received corticosteroids and $12 \%$ treatment with Infliximab. The mean duration of immunosuppressive treatment was 6.9 years $( \pm 5$, 7años). The percentage of total and ocular recurrence was $37.5 \%$ and $31.25 \%$ respectively. The mean duration of follow-up after treatment suspension was 4.3 years ( \pm 4.5 years), being more than 1 year in $77.1 \%$ of patients. We found that $75 \%$ of patients remained free of recurrence at least 27 months. The administration of two or more immunosuppresive drugs proved to be a risk factor for recurrence $(p=0,048)$ and reintroduction of treatment after it $(p=0,008)$, which was performed in $39 \%$ of the ocular recurrences. Visual acuity did not suffer variation in $78.6 \%$ of recurrences and $80.3 \%$ of those that did not recur.

Abstract SAT0595 - Table 1-. Main diagnoses

\begin{tabular}{|c|c|c|c|}
\hline Diagnosis & Female $(n=29)$ & Male $(n=19)$ & All $(n=48)$ \\
\hline Idiophatic uveitis ( $n=13$ ) & $7(53,8 \%)$ & $6(46,2 \%)$ & $13 / 48(27 \%))$ \\
\hline Juvenil idiopathic arthritis ( $\mathrm{n}=1$ ) & $1(100 \%)$ & $0(0 \%)$ & $1 / 48(2,08 \%)$ \\
\hline $\begin{array}{l}\text { Multifocal Choroiditis with } \\
\text { Panuveitis }(n=1)\end{array}$ & $0(0 \%)$ & $1(100 \%)$ & $1 / 48(2,08 \%)$ \\
\hline Serpiginous choroiditis ( $n=3$ ) & $1(33,3 \%)$ & $2(66,7 \%)$ & $3 / 48(6,25 \%)$ \\
\hline Behcet disease $(n=10)$ & $4(40 \%)$ & $6(60 \%)$ & $\begin{array}{c}10 / 48 \\
(20,83 \%)\end{array}$ \\
\hline $\begin{array}{l}\text { Birdshot Retinochoroidopathy } \\
\qquad(n=5)\end{array}$ & $3(60 \%)$ & $2(40 \%)$ & $5 / 48(10,41 \%)$ \\
\hline Inflammatory bowel disease $(n=1)$ & $1(100 \%)$ & $0(0 \%)$ & $1 / 48(2,08 \%)$ \\
\hline Multiple sclerosis $(n=3)$ & $3(100 \%)$ & $0(0 \%)$ & $3 / 48(6,25 \%)$ \\
\hline Ankylosing spondylitis ( $n=1$ ) & $0(0 \%)$ & $1(100 \%)$ & $1 / 48(2,08 \%)$ \\
\hline HLAB27 positive ( $n=1$ ) & $1(100 \%)$ & $0(0 \%)$ & $1 / 48(2,08 \%)$ \\
\hline Pars planitis $(n=2)$ & $1(50 \%)$ & $1(50 \%)$ & $2 / 48(4,16 \%)$ \\
\hline Sarcoidosis $(n=5)$ & $5(100 \%)$ & $0(0 \%)$ & $5 / 48(10,41 \%)$ \\
\hline Vogt-Koyanagi-Harada $(n=2)$ & $2(100 \%)$ & $0(0 \%)$ & $2 / 48(4,16 \%)$ \\
\hline
\end{tabular}

Conclusions: In our cohort, patients with no ocular inflammatory activity for at least two years could benefit from the suspension of immunosuppressive treatment without a visual risk. The use of one or more immunosuppressive drugs has been identified as a risk factor for recurrence.

\section{REFERENCE:}

[1] Update on the principles and novel local and systemic therapies for the treatment of non-infectious uveitis. Inflamm Allergy Drug Targets 2013;12 (1):38-45.

Disclosure of Interest: None declared DOI: 10.1136/annrheumdis-2018-eular.5105

\section{SAT0596 \\ THORACIC INVOLVEMENT AT DIAGNOSIS DRIVES A DIFFERENTIATED CLINICAL PRESENTATION OF SARCOIDOSIS: ANALYSIS OF 1245 PATIENTS (SARCOGEAS-SEMI)}

S. Retamozo ${ }^{1,2}$, P. Brito-Zerón ${ }^{1,3}$, R. Pérez-Alvarez ${ }^{4}$, B. Kostov ${ }^{5}$, C. Feijoo Masso ${ }^{6}$ G. Fraile ${ }^{7}$, R. Gómez-de-la-Torre ${ }^{8}$, B. De-Escalante ${ }^{9}$, M. López-Dupla ${ }^{10}$, A. Alguacil ${ }^{11}$, J. Chara-Cervantes ${ }^{12}$, M. Pérez-Conesa ${ }^{13}$, J. Rascón ${ }^{14}$, J.S. GarciaMorillo ${ }^{15}$, P. Perez-Guerrero ${ }^{16}$, E. Fonseca ${ }^{17}, \mathrm{M}$. Akasbi $i^{18}$, M. Bonet ${ }^{19}, \mathrm{~J}$. L. Callejas ${ }^{20}$, G. De-la-Red ${ }^{21}$, E. Calvo ${ }^{22}$, C. Soler ${ }^{23}$, E. Peral-Gutiérrez ${ }^{24}$, J. F. Gómez-Cerezo ${ }^{25}$, G. Cruz-Caparrós ${ }^{26}$, S. Rodríguez-Fernández ${ }^{27}$, B. Pinilla ${ }^{28}$, A. Gato ${ }^{29}$, A. Rolo ${ }^{30}$, C. Morcillo $^{3}$, A. Robles ${ }^{31}$, I. Ojeda ${ }^{32}$, M.J. Vives ${ }^{33}$, B. de Migue $^{34}$, M. Penadés ${ }^{35}$, M. De-Vicente ${ }^{36}$, X. Bosch ${ }^{1}$, M. Pérez-de-Lis ${ }^{4}$, A. González-García ${ }^{7}$, C. Yllera ${ }^{8}$, B. Gracia-Tello ${ }^{10}$, A. Perez-Gonzalez ${ }^{4}$, M. Pedrosa ${ }^{6}$, C. Tolosa 6 , L. Pallarés ${ }^{14}$, M. Ramos-Casals ${ }^{1} .{ }^{1}$ H. Clinic, Barcelona, Spain; ${ }^{2}$ H. Privado Córdoba, IUCBC, CONICET, Cordoba, Argentina; ${ }^{3} \mathrm{H}$. CIMA Sanitas, Barcelona; ${ }^{4} \mathrm{HAC}$, Vigo; ${ }^{5}$ IDIBAPS CAP Les Corts, Barcelona; ${ }^{6} \mathrm{H}$. Parc Tauli, Sabadell; ${ }^{7}$ H. Ramon y Cajal, Madrid; ${ }^{8}$ HUCA, Oviedo; ${ }^{9}$ H. Clinico, Zaragoza; ${ }^{10} \mathrm{H}$. Joan XXIII, Tarragona; ${ }^{11} \mathrm{H}$. Virgen de la Salud, Toledo; ${ }^{12} \mathrm{H}$. Josep Trueta Girona; ${ }^{13} \mathrm{H}$. Miguel Servet, Zaragoza; ${ }^{14} \mathrm{H}$. Son Espases, Palma de Mallorca; ${ }^{15} \mathrm{H}$. Virgen del Rocio, Sevilla: ${ }^{16} \mathrm{H}$. Puerta del Mar, Cadiz; ${ }^{17} \mathrm{H}$. Cabueñes, Gijón; ${ }^{18} \mathrm{H}$. Infanta Leonor, Madrid; ${ }^{19}$ Althaia, Manresa; ${ }^{20} \mathrm{H}$. San Cecilio, Granada; ${ }^{21} \mathrm{H}$. Esperit Sant, Santa Coloma; ${ }^{22} \mathrm{H}$. San Jorge, Huesca; ${ }^{23} \mathrm{H}$. Sta Caterina, Girona; ${ }^{24} \mathrm{H}$. Virgen Macarena, Sevilla; ${ }^{25} \mathrm{H}$. Infanta Sofía, Madrid; ${ }^{26} \mathrm{H}$. Poniente, Almería; ${ }^{27} \mathrm{H}$. Barbanza, A Coruña; ${ }^{28} \mathrm{H}$. Gregorio Marañón, Madrid; ${ }^{29} \mathrm{CH}$ General, Albacete;

${ }^{30} \mathrm{H}$. Salamanca, Salamanca; ${ }^{31} \mathrm{H}$. La Paz, Madrid; ${ }^{32} \mathrm{H}$. Valle del Guadiato, Cordoba; ${ }^{33}$ Parc Sanitari San Joan de Déu, Sant Boi; ${ }^{34}$ H. 12 de Octubre, Madrid; ${ }^{35} \mathrm{H}$. Manises, Valencia; ${ }^{36} \mathrm{H}$. Nuestra Señora del Prado, Talavera, Spain

Objectives: To analyse whether thoracic involvement at diagnosis is associated with a specific clinical presentation of sarcoidosis.

Methods: The SARCOGEAS-SEMI is a nationwide registry of patients with sarcoidosis. Radiographic stages at diagnosis were classified as stage 0 (normal), stage I (only bilateral hilar lymphadenopathy -BHL-), stage II (BHL + pulmonary infiltrates), stage III (only infiltrates) and stage IV (fibrosis).

Results: The cohort consisted of 1245 patients ( 722 women, 523 men, mean age at diagnosis 47 years). Pulmonary imaging data at diagnosis was available in 1230 patients including $395(32 \%)$ with stage I, $500(40 \%)$ with stage II, $195(16 \%)$ with stage III and $42(3 \%)$ with stage IV. Patients with no thoracic involvement (stage 0 ) were more frequently women $(73 \%$ vs $56 \%, p=0.002)$, older $(52.1$ vs 46.8 years, $\mathrm{p}=0.001)$ and had a higher frequency of skin ( $54 \%$ vs $34 \%, p<0.001)$ and neurological ( $14 \%$ vs $6 \%, p=0.004)$ involvements in comparison with those with stages I-IV. Patients without ILD (stage I) were more frequently women $(61 \%$ vs $54 \%, p=0.031)$, had a higher frequency of fever ( $27 \%$ vs $19 \%, p=0.002)$, skin $(43 \%$ vs $29 \%, p<0.001)$ and salivary gland involvement $(8 \%$ vs $3 \%, p=0.001)$, and a lower frequency of respiratory symptoms $(37 \%$ vs $54 \%, p<0.001)$ and liver involvement ( $9 \%$ vs $16 \%, p=0.001$ ) with respect to those with ILD (stages II-IV). Conclusions: A specific clinical and epidemiological pattern of disease presentation was found in patients with no thoracic involvement and in those presenting with interstitial lung disease at diagnosis.

Disclosure of Interest: None declared

DOI: 10.1136/annrheumdis-2018-eular.4161

\section{SAT0597 NEW AUTOINFLAMMATORY PHENOTYPE MANIFESTING AS HYPOCOMPLEMENTEMIC URTICARIAL VASCULITIS AND ASSOCIATED WITH HOMOZYGOUS AGBL3 VARIANT}

A. Gül ${ }^{1}$, N. Abaci' ${ }^{2}$, S. Sirma Ekmekci ${ }^{2} .{ }^{1}$ Department of Internal Medicine, Division of Rheumatology, Istanbul University, Istanbul Faculty of Medicine; ${ }^{2}$ Department of Genetics, Istanbul University, Institute for Experimental Medicine, Istanbul, Turkey

Background: Autoinflammatory disorders are primarily associated with inborn errors of the innate immune system, but some of them are also developing autoimmune features.

Objectives: To define a new autoinflammatory phenotype in a patient with inflammatory attacks manifesting as hypocomplementemic urticarial vasculitis and to identify responsible gene/pathway.

Methods: Clinical manifestations of the index case and his family history were carefully searched and blood samples were collected from the index case and his both parents. Genomic variations were screened by whole exome sequencing, 